\title{
IGNITION OF THE SOARING DROPLET SETS OF WASTE-DERIVED COAL-WATER SLURRY WITH PETROCHEMICALS
}

\author{
Timur R. Valiullin ${ }^{1, *}$, Margarita A. Dmitrienko ${ }^{1}$, Sergey A. Shevyrev ${ }^{1}$, and Roman I. \\ Egorov $^{1}$ \\ ${ }^{1}$ National Research Tomsk Polytechnic University, 634050 Tomsk, Russia
}

\begin{abstract}
We have analyzed the ignition of droplet sets of waste-derived coal-water slurry with petrochemicals for the case of their soaring inside special combustion chamber. The fuel composition consists of filter cake of bituminous coal type $\mathrm{G}$, waste turbine oil, water and plasticizer. Features of the ignition process were emphasized for groups of three soaring droplets in comparison with single droplet ignition. The ignition delay times were registered for particles that were deformed or segregated due to the interaction of initial fuel droplets with walls of the combustion chamber.
\end{abstract}

\section{Introduction}

The large scale usage of the oil-products in transportation, chemical industry, heat and electricity production, etc. leads to production of the huge amount of different types of wastes (like waste engine oils or oil sludge). Its amount is quickly growing year per year and nowadays it achieves millions tons per year. [1-3]. Together with this the coalprocessing wastes breaks records and now it is near billion tons per year. The accumulation of these wastes is an evidently sharp and still growing problem for whole humanity. The development of the optimal method of the effective utilization of such wastes is actual task for different countries. The waste-derived coal-water slurries with petrochemicals (CWSP) become now the perspective type of alternative fuels for industrial heat production [3]. It can produce enough much heat energy together with strong decrease of waste production for different branches of world industry.

There are some well-known approaches for investigations of the peculiarities of initialization of stable combustion [4-7] that typically used for investigation of the composite fuels. The most popular is introduction of the single fuel droplets into the combustion chambers or high-temperature air channels by usage of the different holders like quick-response thermocouple junction, the ceramic thread or thin metal wire.

The main integral parameters of ignition and combustion of fuel suspensions or at least droplet sets have to be investigated for further effective usage of the CWSP at the industrial heat-producing units. The main way of the industrial usage of the CWSP is injection of the

* Corresponding author: radisovich@yandex.ru 
fuel aerosol flow to the combustion chamber through the nozzle. Therefore the influence of the droplet interaction with walls of combustion chamber and with other droplets, its coagulation, segregation etc. becomes an important factor determining the parameters of the ignition and combustion processes. As result, we offer the method allowing the investigation of ignition of fuel droplet sets as well as single droplets in case of its free soaring in the hot oxidant flow (air) inside the special combustion chamber [8]. The presented approach doesn't need any holders for fuel droplets and allows observations of the combustion process as it is inside industrial chambers.

The aim of this work is determination of the main integral parameters of ignition of the droplet sets (three CWSP droplets in each) together with comparison of these data with corresponding to ignition of the single droplet in soaring regime.

\section{Experimental procedure}

The experimental setup and the used method are similar to described in [8]. Determination of the integral parameters of the single fuel droplets and droplet groups in soaring regime was done using special combustion chamber. It was made of heat-resistant quartz glass specially developed for optical measurements of the combustion processes. The heating and pumping system allows setting and keeping of the temperature and the velocity of the air (oxidant) flow in ranges $600-900 \mathrm{~K}$ and $0.5-3 \mathrm{~m} / \mathrm{s}$ correspondingly. The flow temperatures at different point of combustion chamber were controlled by two chromel-alumel thermocouple (working range $273-1373 \mathrm{~K}$, bias $\pm 3 \mathrm{~K}$, response time $\sim 3$ s). All the experiments were done at random variations of the initial flow temperature less than $5 \mathrm{~K}$ and for velocity less than $0.1 \mathrm{~m} / \mathrm{s}$.

Unlike to experiments presented at [8] the introduction of three fuel droplets into the chamber (and their synchronized ejection) was done by specially developed device (fig. 1). It consists of three conjugated similar elements (fig. 1a). The sub-elements were connected at an angle to one another together with small lateral shift to simplify the recharge by the fuel. The CWSP droplets were created by the batcher Finnpipette Novus. Its size was additionally checked before the introduction to combustion chamber by video frames analysis at Tema Automotive software package.

The synchronized droplet ejection was done by motorized system conjugated with system of fuel introduction into the combustion chamber. Cutting element - 3 ejects the droplet (fig. 1a) from the nichrome holder - 2 when it achieves the center of the combustion chamber.

The analysis of the video records of the soaring droplet combustion was done using special abilities of the Tema Automotive package allowing continuous tracking of the moving objects and checking of their brightness to determine the ignition delay times for each fuel droplet $\left(\tau_{d}\right)$ like it was done in [8].

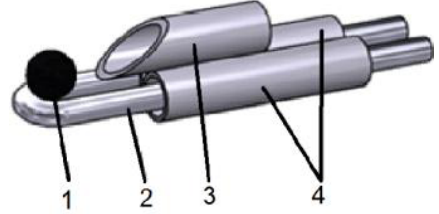

a)

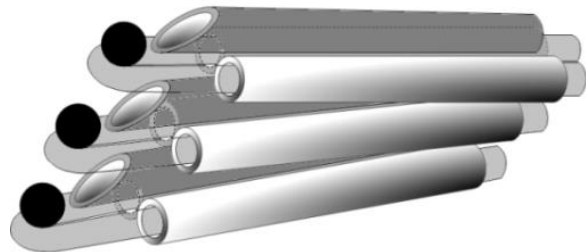

b)

Fig. 1. Scheme of the droplet ejection device. The single droplet ejection module (a). There are: $1-$ the CWSP droplet; 2 - thin nichrome wire; 3 - cutting element; 4 - metal guiding pipe. The synchronized ejection device for three fuel droplets (b) consists of three modules presented at (a). 
The main component of the fuel composition is filter cake of the bituminous coal type "G" which appears during the floatation enrichment of the coals. Nowadays, there are more than 10 coal-enrichment factories at Siberia region produces hundred thousands of filter cakes per year. The filter cake incorporates $40-50 \%$ of the solid coal matter and $50-60 \%$ of water. The second combustible component of the CWSP fuel is waste turbine oil. The "Neolas" plasticizer was used for stabilization of the fuel composition for long term storage (1-2 weeks) without essential lamination of the slurry. The component ratio of the chosen CWSP is shown in table 1.

Table. 1. The CWSP content (relative mass ratios of the components).

\begin{tabular}{|c|c|c|c|}
\hline Coal, \% & Liquid combustible, \% & Water, \% & Plasticizer, \% \\
\cline { 1 - 2 } $\begin{array}{c}\text { Filter cake of coal } \\
\text { type "G" }\end{array}$ & Waste turbine oil & 39 & 0.5 \\
\hline 50.5 & 10 & \\
\hline
\end{tabular}

\section{Results and discussion}

The changes of the ignition delay times $\left(\tau_{d}\right)$ with oxidant flow temperature are shown at fig. 2. Each of presented curves is approximation of the measured points obtained during the set of experiments. The typical errors are less than $10 \%$ of the measured values.

The differences of the ignition delay times of three droplets inside the certain set are near $1.5 \mathrm{~s}$ that could be explained by their random interaction with walls of the combustion chamber. The collisions between droplets were relatively rare due to its low density inside the chamber volume and therefore didn't make essential influence onto the ignition parameters. However, this effect should be taken into account for real combustion chambers which works with the highly dispersed fuel droplet flows.

The droplets inside the chamber fly along different and enough complicated trajectories that leads to random oscillations of the measured ignition delay time due to non-uniform temperature distribution inside. The experimental data analysis makes clear that the temperature dependence of the ignition delay for low density droplet flow is present in between the curves 1 and 4 (the shaded are at fig. $2 a$ ).

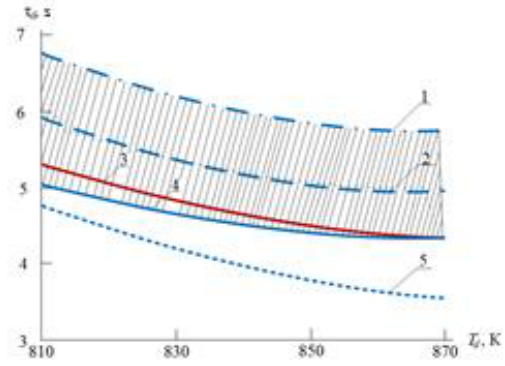

a)

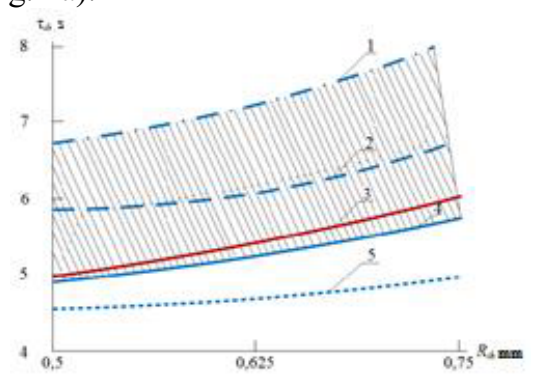

b)

Fig. 2. The dependences (a) of the CWSP ignition delay time with oxidant flow temperature at $R_{\mathrm{d}}=0.5$ $\mathrm{mm}$ and $V_{\mathrm{g}}=3.5 \mathrm{~m} / \mathrm{s}$. The ignition delay time changes with CWSP droplet size (b) at $T_{\mathrm{g}}=813 \mathrm{~K}$. Curves 1, 2, 4 corresponds to ignition of the first, second and third droplets in order of ignition events. The curve 3 corresponds to ignition of the single droplet inside the chamber. The curve 5 corresponds to ignition of typical small secondary droplets segregated from one of the initial set due to collision with chamber walls. 
The experiments have demonstrated that droplets collisions with chamber walls can produce small segregated droplets. These fuel particles ignite evidently faster than initial big droplets that could be valuable for real combustion chambers with massive droplet flows decreasing total ignition inertia. These effects could be the subject for future investigation tasks.

The fig. $2 \mathrm{~b}$ presents the dependences of the ignition delay times for CWSP droplets on droplet sizes. The variations of the droplet radius for $15 \%$ relatively median value $\sim 0.62$ $\mathrm{mm}$ lead to changes of the $\tau_{d}$ for $0.5-1 \mathrm{~s}$. This median size is close to typically used at industrial combustion chambers. The demonstrated changes of the $\tau \mathrm{d}$, caused by variations of the droplet size are very similar to thermally induced ones shown at fig. $2 \mathrm{a}$.

Together with all mentioned, the secondary droplets appearing during the destruction of the initial ones, has ignition delay times which almost don't change with initial particle sizes (fig. 2b). Most probably it is possible to make fuel slurries that effectively ignore the random temperature oscillations inside the combustion chamber, using an optimal ratio of the droplet sizes inside the injected fuel flow. Such droplet flows will have more stable ignition and following combustion.

The main result of the investigations is definition of the ranges of the ignition delay times for sets of the droplets which allows the interpolation of obtained data to the case of low-density fuel droplet flows. The mutual arrangement of the shaded ranges at the fig. 2 and the dependencies for ignition parameters of single droplets illustrates weak cointeraction of the droplets inside the set and its influence onto the ignition processes. This conclusion is important for justification of practical applicability of the approach with single CWSP droplet ignition for generalization of the results to the case of processes inside full-scale combustion chamber.

\section{Conclusion}

1. The ignition delay times inside the set of the fuel droplet have differences $\sim 0.5-1 \mathrm{~s}$ with median value $\sim 6 \mathrm{~s}$ at observed oxidant flow temperature range. The integral characteristics of ignition of single droplet well correlate with this range. This result illustrates that prediction of the ignition characteristics of droplet set could be effectively done by observation of single droplet ignition.

2. The analysis of influence of the CWSP droplet sizes onto the ignition delay times shows relatively small variation of the ignition delay for certain range around industrially appropriate median size $(0.6 \mathrm{~mm})$. It allows to make the droplet flows with stable integral parameters of the ignition by optimal mixing of different size droplet fractions.

3. The relatively small ignition delay times detected for small secondary droplets, which always appear from the initial ones inside real chambers, allows estimating the lower threshold of ignition delay at 4-5 s for different sizes of the initial droplets.

\section{Acknowledgments}

This work with ignition processes of CWS supported by the Russian Science Foundation, project 15-19-10003. The environmental impact of CWS was investigated within the program of National Research Tomsk Polytechnic University Competitiveness Enhancement in the Group of Top Level World Research and Academic Institutions (project VIU_ENIN_25_2016). 


\section{References}

1. O.G. Chayka; O.Z. Kovalchuk; Y.A. Chayka, Monitoring the formation of waste oils. Proceedings Scientifical works (Lviv Polytechnic, Lviv, 2009) [in Ukrainian]

2. G. Hu, G. Zeng, J. Hazard. Mater. 261 (2013)

3. A.E. Kontorovich, M.I. Epov, L.V. Eder, Russian Geol. Geophys. 55, 5-6 (2014)

4. W. Gajewski, A. Kijo-Kleczkowska, J. Leszczynski, Fuel 88, 2 (2009)

5. A. Kijo-Kleczkowska, Fuel 90, 2 (2011)

6. D.O. Glushkov, D.P. Shabardin, P.A. Strizhak, K.Yu. Vershinina, Fuel Process. Technol. 143 (2016)

7. D.O. Glushkov, P.A. Strizhak, K.Yu. Vershinina, Appl. Therm. Eng. 96 (2016)

8. T.R. Valiullin, P.A. Strizhak, S.A. Shevyrev, Therm. Sci. Online First. $10.2298 / \mathrm{TSCI} 151215221 \mathrm{~V}$ 